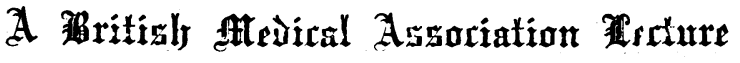 ox}

\section{CARCINOMA OF THE STOMACH.}

Delivered before tile Sotth-TVest Wales Division on Apkil 17TH, 1929,

BY

\section{A. J. WAT.TON, M.S., F.R.C.S., SLRGEJN TO THE LONDON HOSPITAL.}

OF the $\varepsilon 62$ patients with carcinoma of the stomach that have sought mr advice, 9 , and 9 onlv, have survived for a long enough time for me to regard them as probable cures. These figures are sufficiently startling to make us realize that all is not well with our methods of diagnosis and treatment of this discase. In other varieties of carcinoma somewhat letter results are clbtained, but they are still far from satisfactory, and for this reason no one disease has at any stage in the history of the medical world attracted so much attention as has cancer to-day. I therefore feel rers sensible of the honour which rour committee has done me in asking me to consider with you some of the problems which confront us in dealing with the difficult subject of carcinoma of the stomach. On all sides efforts which are almost feverish in their activity are being made to discover its cause and cure, and although there have been no startling discoveries, it is satisfactory to realize that methods which are more or less empiric are little br little adding to our store of knowledge and are steadily improving our results. In some forms of cancer, indecd, the use of radium and $x$ rays has been a great advance on the older methods.

\section{Friologr.}

Carcinoma of the stomach is so difficult to diagnose in its early stages that anr improvement in our results must of necessity be slow, and can only be recognized if we have accurate statistical knowledge of the present-dar position of the disease. It is generally believed that it is increasing in frequencr, but, as $I$ have proviously pointed out, ${ }^{6}$ my figures do not support this riew. They are small in number, but are of value in that every case has been proved by operation, supported either by microscopic examination or by carefur obserration of the afterprogress of the paticnt. The figures (sce Chart 1) show

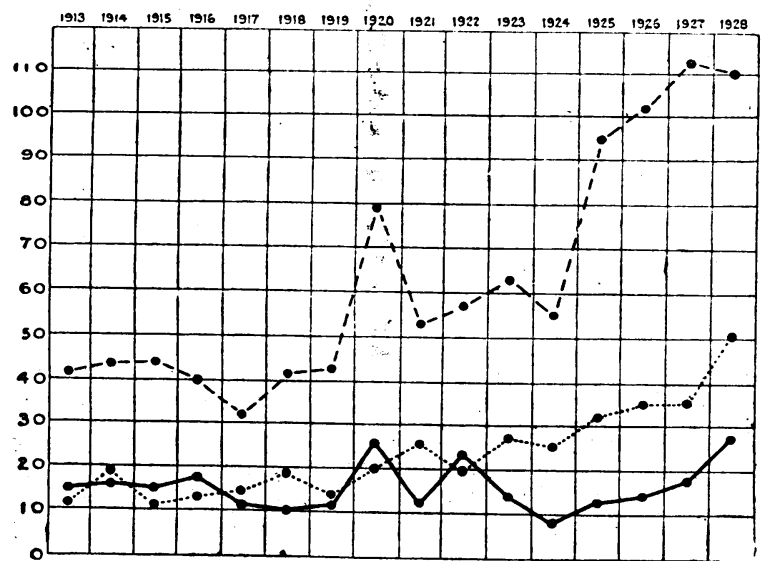

Chart I.-Frequency of carcinoma and chronic ulceration. Total oases of carcinoma 262 (males 191, females 71). Total cases of chronic ulcer 1,141 (males 850, females 291). Continuous line= ; interrupted line=all ulcers; dotted line=lesser curve

a considerable rariation in the number of cases treated each year, but no steady or regular rise since 1913 . The interesting point is also noticeable that the numbers have remained more or less steady in spite of the fact that the chronic ulcers for which they are often mistaken have shown a very marked and rapid increase in numbers. There has thus been a relative decrease in the numbers of carcinomata, so that whereas in 1913 they formed about one-third of all my gastric operations, they now form only about one-sixtl. The explanation which $I$ hare given for this, and which I still believe to be correct, is that a large number of cases of carcinoma of the stomach are prevented because they are opcrated upon while they are still benign ulcers. An apparent increase in the RegistrarGeneral's figures may be due to the fact that the average age of the population is being raised, for the disease is most common between the ages of 50 and 60 , more than threequarters of the cases occurring between the ages of 40 and 70 . Nevertheless, it must always be remembered in considering the diagnosis of a gastric lesion that carcinoma may occur at a much younger age. In my own series 3 cases occurred under the age of 30 (Chart 2), but Sullivan, 5 who reported a proved example of the discase in a patient of 22 , was able to collect from the literature 21 patients under the age of 25 .

One of the most interesting facts of carcinoma as a whole is the varying sex incidence in the different varieties of the disease. With carcinama of the stomach the male sex is much more frequently affected. Thus, in my own series of 262 cases, 191 were males. This may to a certain extent be due to the fact that some of the carcinomata are secondary to chronic ulcers, for with

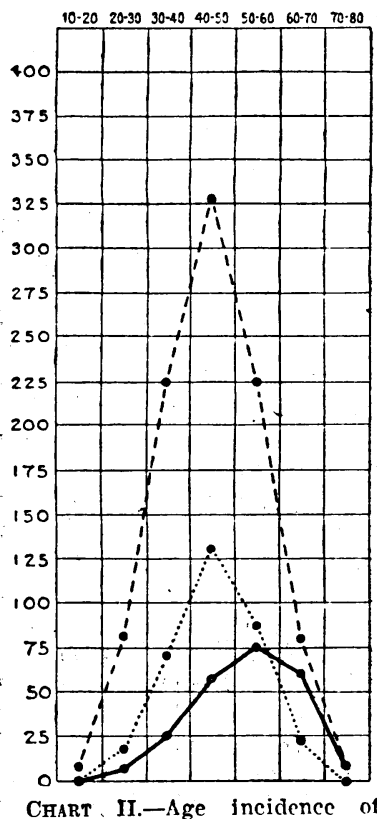
Chart 、II.-Age incidence of Continuous line=carcinoma ; in crrupted line=all ulcers; dotted line=lesser curve ulcers. chronic peptic ulcers the incidence in males is even more marked. There were, for instance, in my own series of 1,141 chronic ulcers, 850 males.

\title{
PatholoGi.
}

Carcinoma of the stomach is almost wholly a primary disease. A few rare cases which are secondary-most frequently to carcinoma of the breast-have been reported, and there are others where the disease has spread to the stomach by direct extension from the gall-bladder, colon, or pancreas. In the viscus itself some of the carcinomata at the cardiac end are squamous in character, and have then almost certainly spread from the oesophageal opening. The softer, more medullary types of such disease may, instead of constricting the lower end of the oesophagis, spread down along the lesser curvo and cardia, and give rise to a neoplasm which clinically is gastric rather than oesophageal. To-day this distinction is not of great importance, but if the operation of removal of the cardiac end of the oesophagus becomes more general, the differentiation of these two types will beconte of considerable practical importance.

The common variety of carcinoma of the stomach arises from the glandular elements, and the different types, therefore, depend upon varying degrees of differentiation of the cells, or upon secondary changes in the lost. If the cells are well differentiated they may become columnar in shape and grouped intō the form of immature gland tubules. Such a type is spoken of as an adenocarcinoma, and generally forms a fungating mass in the region of the pylorus. There is, however, no sharp line of differentiation between this variety and the more common types. Usually a combination of some columnar cells grouped into incomplete tubules with masses of cuboidal cells is found:

An intercsting variety is that in which the cells sliow a colloidal change to form semi-transparent globules visible to the naked eye. The change appears to be inherent in the epithelium, for it is not only visible in the primary growth, but also in the cells of the-secondary deposits. Occasionally masses of unchanged cells are seen lying in large spaces formed of colloid material. Although this 
change is generally spoken of as a colloidal degeneration, there is no evidence that it is relatively benign. In the cases in my own series there have usually been large masses of secondary deposits in the coronary glands. Stimson, ${ }^{4}$ who studied 121 examples of this variety occurring at the Mayo Clinic, found that they formed about 5 per cent. of all gastric carcinomata, and that the percentage living three and five years after operation was about the same as with the non-colloidal types.

The common pathological types vary in their appearance, if not in their prognosis, according to the reaction of the host and the consequent fibrosis. Those in which there is but little fibrosis are usually described as medullary types. These most commonly occur on the lesser curve, and form large, soft, raised, fungating masses which widely infiltrate the wall of the stomach and frequently ulcerate. There is, however, an interesting variety to which I have on several occasions directed attention. It occurs on the greater currature of the stomach, grows relatively slowly, and forms a large mass projecting into the stomach, but seems to be relatively benign, and is only associated with secondaries comparatively late (Fig. 1 ). It is of considerable practical importance in that it may give rise to a relatively enormous tumour, which, because of its size, may be regarded as inoperable, but if an operation be undertaken is found to be easily removable. Owing to its site and rather abnormal characters, it would seem most likely that it occurs as a malignant change in a simple papilloma.

The scirrhous types with more massive fibrosis are most commonly found at the pylorus, and form smaller masses

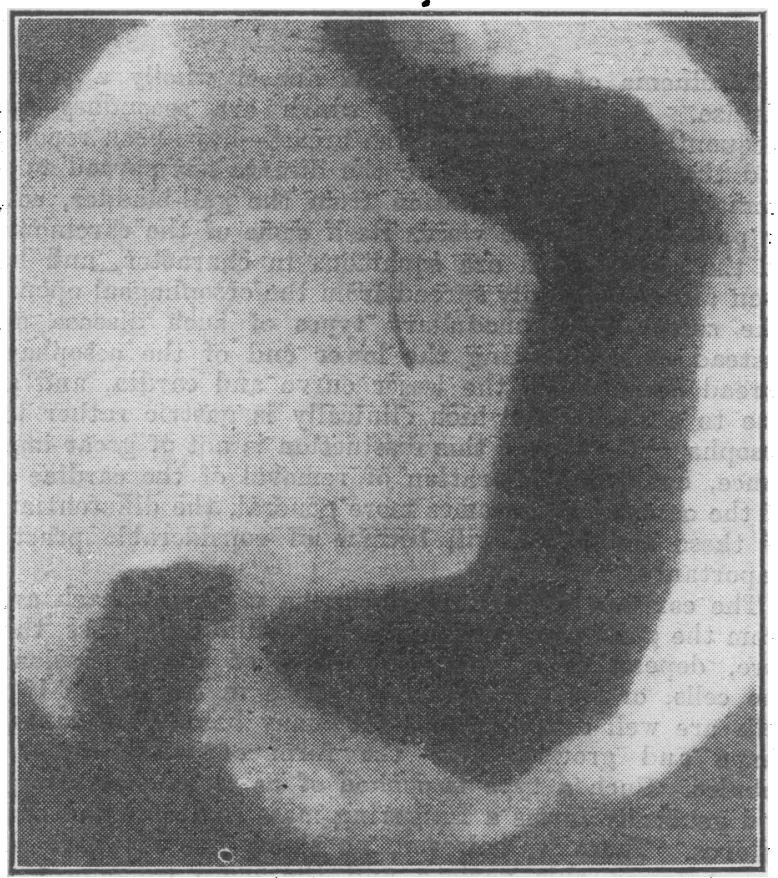

Fig. 2.-Radiogram of " leather-bottle" stomach.

which infiltrate and replace the walls of the stomach. The fibrous tissue contracts and leads to stenosis, and the mucous surface undergoes shallow ulceration. When situated at the lesser curve it tends to spread round the walls of the stomach, and thus gives rise to an hour-glass deformity, which differs from the common type secondary to an ulcer in that the constricted passage is relatively long and irregular and is centrally placed, so that the greater curve is not drawn up to the lesser as with an ulcer.
This variety of hour-glass constriction may occur with either sex, while the simple type is almost, if not indeed entirely, limited to females, and hence if a male patient is found to have an hour-glass deformity of the stomach a carcinoma should always be suspected. These variation: in the reactions of the host are, however, no indication of the malignancy of the condition. A scirrhous carcinoma of the pylorus is not infrequently seen which from its local characters admirably lends itself to resection, but which is associated with widespread secondary changes in the liver or in other viscera. The massive carcinoma of the ovaries, known as the Krukenberg tumour, is usually secondary to a small scirrhous growth of the stomach.

The most extreme degree of reactive fibrosis is found with the condition known as "leatherbottle stomach," or "linitis plastica." It. is relatively rare, and my own series only includes four examples. There has been much discussion as to its nature, and a certain amount of evidence has been produced to show that it may occur secondary to an in type. Every example in my own practice and in the hospital has, however, been carcinomatous in nature. Sometimes so widespread is the fibrosis that small groups of isolated carcinoma cells may only be found in the stomach wall or in the glands after many microscopic sections have been made. I am therefore of the opinion that all true cases of this condition are of the nature of an atrophic scirrhous carcinoma. The affected stomachś show a remarkable similarity. In the diffuse type the whole viscus is much contracted (Fig. 2), and the wall is enormously thickened and rigid. The peritoneal surface is usually normal in appearance, or may show scattered white patches of infiltration. The change is abrthtly limited to the pylorus, and may extend right $\left.u_{i}\right)$ to the oesophagus or leave but a small area at the cardia unaffected. Although the stomrach lesion is so widespread

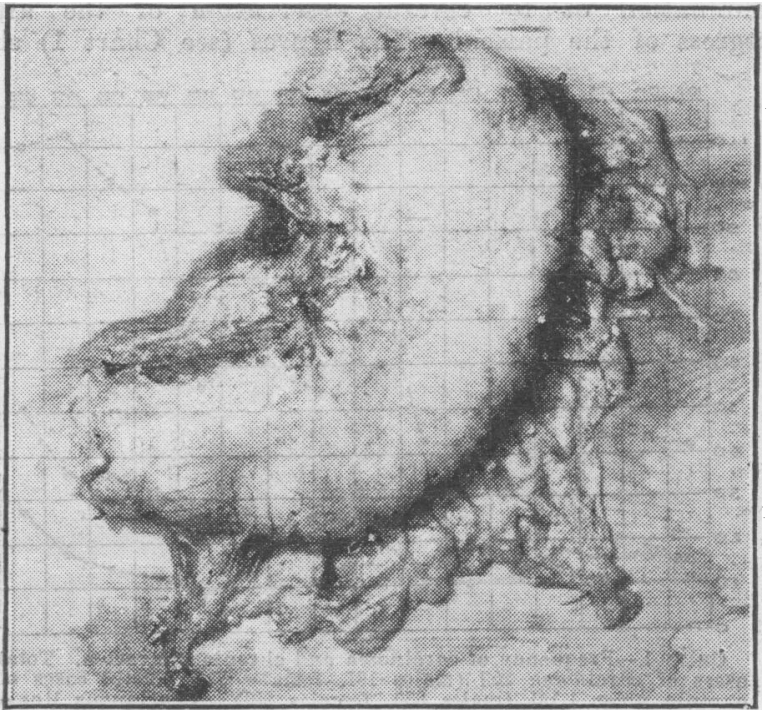

FIG. 3.-Stomach from case seen in Fig. 2 after removal (complete gastrectomy)

the change is relatively benign, so that the glands may be but little affected, and the operation of complete gastrectomy, although associated with a high mortality, may hold out hopes of a cure.

One of the most important facts which will influence us in the treatment, and especially in the preventive treatment, of carcinoma is its relation to chronic gastric ulcer, a relation which of late years has been the subject of much diversity of opinion. As far back as 1839 Cruveilhier and 
Rokitansky first suggested that there might bo such a relationship, and later Osler and others found that about 5 per, cent. of the carcinomata had originated in such ulcers. Some years later-that is to say, about fifteen years agothe relationship was regarded as much more close, MacCarty suggesting that some 70 per cent. of all carcinomata commenced in this way. This figure was manifestly too high, and, bcing disproved, has tended to make opinion sway too far in the opposite direction-an opinion which is fostered by those who believe in the medical treatment of gastric ulcers, for it is evident that if there were a danger of the ulcer becoming malignant the routine use of medical treatment would be a dangerous procedure. Stewart's ${ }^{3}$ careful pathological figures are very helpful. He came to the conclusion that 9.5 per cent. of chronic ulcers became malignant, and that 17 per cent. of the cases of cancer originated in an ulcer. I have previously reported a carefully analysed series of 229 of my own cases of carcinoma from this point of view, and have only grouped as having an arigin in an ulcer those which fulfilled the following requirements :

1. 'They must have a history of many years' standing in which the earlier symptoms were periodic.

2. They must have at the time of operation a relatively high test meal.

3. They must present at operation the characteristic appearance of an ulcer.

4. The pathological report must strongly suggest that the carcinoma was secondary to an ulcer.

Twenty-fivo cases fulfilled these requirements-that is, 10 per cent. of the total-but, as the inoperable cases could not be included, this is almost certainly an underestimate. The more important consideration, however, to us is the percentage of cases which, although not truly benign ulcers, are at first diagnosed as such and later become carcinomatous, for it is in these that the great mistake may be made in continuing medical treatment until the condition is hopelessly inoperable. Scott ${ }^{2}$ has laid stress upon this, and has found that 15 to 20 per cent. of clinically diagnosed ulcers become malignant. The importance of the pathological relationship lies in the fact that if we can remove, while they are yet benign, those ulcers which, if left, would become malignant, we shall $\cdot$ do much to prevent the onset of carcinoma and to lessen the mortality of this dread disease. Moreover, in our clinical investigations, and in our operations, we must always consider the possibility of such a complication, and if there be any suggestion of its presence a more extensire operation must be performed.

\section{Srmprésis.}

The sumptomatology of carcinoma of the stomach has had so much attention directed to it that it might be thought that it was unnecessary to consider it in detail, but the cases are so often slow and insidious in their onset that they are still frequently overlooked, and it is only by careful consideration of the finer points of the symptoms that an accurate diagnosis can be made, or that even a suspicion of the presence of the disease is aroused. The most frequent variety of carcinoma of the stomach is that which arises in the body of the viscus, and in this position the disease may present itself slowly and insidiously, or arise with a sudden onset, or the symptoms of a gastric ulcer may slowly and gradually. change to those of a carcinoma. In the first two varieties the most important factor is without question the presence of a short history of dyspepsia occurring in a patient of middle age who has previously been free of all gastric symptoms, and I am always in the habit of teaching that such a patient must be regarded as having a carcinoma until he can be proved to be free from it. If the onset is slow and insidious, the first symptoms are usually other than gastric. The patient will complain of a general weakness, loss of energy, and inability to concentrate upon his work, a certain amount of sleeplessness, and possibly some loss of weight. It may, indeed, only be on cross-examination that ho will acknowledge that there is a loss of appetite, and at a later stage there will be a feeling of discomfort after meals, which may even develop into definite pain. Rarely does this become severe, but it tends to persist throughout the day, although it may be exaggerated by the taking of food. The loss of appetite increases, and is nearly always a marked symptom, until it becomes an absolute distaste for all food.

Vomiting is rarely marked, and frequently only amounts to the regurgitation of a small amount of fluid, which the patient will describe as being foul or offensive in character. Regurgitation of food gives little or no relief to the pain. Blood in the vomit is extremely variable, and is often absent to naked-eye investigation. It is only in a relatively small proportion of cases that the presence of altered blood giving the typical coffee-ground vomit is apparent. A severe haemorrhage is not uncommon, although it is perhaps more frequently found in those cases with a sudden onset. If use is made of chemical investigation blood will be found in a much higher percentage of cases. As the disease progresses the patient will show a steady loss of strength and the onset of anaemia. In some cases the latter is a very marked factor, so that the weakness, the depression, and the loss of appetite are regarded as symptoms of a primary anaemia, and indeed at times the blood count may more closely simulate a primary than a secondary anaemia.

On examination, beyond the anaemia, weakness, and wasting, but little may be found. If there is a tumour it is, of course, suggestive of the presence of a carcinoma, but it must never be forgotten that a considerable proportion of these cases have tho lesion high up on tho lesser curve, so that a tumour may not be felt until the patient is in the last stages of the disease. On the other hand, the presence of a tumour itself is no indication that the condition is inoperable. Such a mass will be most easily felt when the lesion is seated at the pylorus, and it is this type of case which gives the best possibility of a partial gastrectomy. If the case has been of sudden onset, the patient will much more frequently complain of severe pain. He may be able to date this back to some specific meal, but the pain never disappears, as it would if duo to an error of diet. In other cases the sudden onset is due to the presence of severe haematemesis, or, more rarely, to a perforation. The important point always to remember, however, is that, whatever the nature of the onset, carcinoma is much the more likely cause of a dyspepsia arising for tlite first time in a patient at or about the age of 40 .

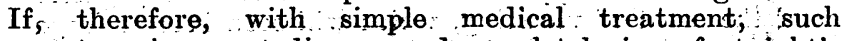
symptoms have not disappeared completely in a fortnight's time, the patient must not bo watched until the diagnosis makes itself evident by the onset of severe symptoms and tho presence of a tumour, but immediate investigation with a test meal and $x$ rays must be carried out

When the disease has arisen secondary to an ulcer, even these methods of investigation may fail, for they may present the characters of the pre-existing ulcer rather than those of a secondary carcinoma: To those of us who believe, as I most certainly do believe; that a persistent chronic ulcer should always be treated by surgical measures, thero is much less chance of making a mistake. A careful analysis of the symptoms will reveal the fact that the pain is becoming more continuous though less severe; that the appetite is beginning to fail and that the pain is not relieved by romiting. In such circumstances there will be a tendency, which may be increased by the appearance of the lesion at operation, to perform a partial gastrectomy rather than a local operation upon the ulcer

Test Meal. - In cases of doubt a careful investigation of the test meal will of ten be of very great help: There is no condition which is associated with so early and complete a loss of the free acid and a diminution of the total acidity.. It is true that a gastritis commencing in a man of middle age: will often have an achlarhydria; and it may require very careful clinical investigation and consideration of all the evidence at our disposal to make a differential diagnosis. Although more difficult to carry out, a fractional test meal undoubtedly supplies more information than the ordinary Ewald meal, for the acidity is not only low, but there is a complete absence of free hydrochloric acid throughout the whole period of the investigation. The value of this test, if taken for the first time on the patient, must be discountenanced whën there has been a previous chronic ulcer. I have had the opportunity on several occasions of examining a test meal on patients who have had a previous meal taken when they still had 
a chronic ulcer, and in every case there has been a marked diminution of the acid, but the important point to remember is that althourgh there has been this diminution the acid may still be above normal, and hence if this had been the first meal talken there wonld have been no indication of the presence of carcinoma.

$X$-ray Investigation.-It is necessary to-day to issue a warning as to the indiscriminate use of $x$-ray investigation. If the investigation is carried out by a skilled observer and a careful report made of the findings on screening, this is one of the most valuable means of diagnosis at our disposal, but if, as is so often done to-day, one or two films are taken by a man but little versed in the method, the findings are not only useless, but nray be positively misinforming and dangerous. In the early stages of the disease an investigation, although performed by a skilled technician, may reveal but little. The most useful sign at this stage will probably be the absence of peristaltic waves over a small portion of the stomach. These may be revealed on the screen, or several films nray be superimposed and may show that, whereas the gerreral contour of the stomach is altered, there is a small area which remains absolutely unchanged. In the later stages filling defects, irregularities of the lesser or greater curve and the presence of a large irregular meniscus will, of course, be self-evident signs. A difficulty often arises in the cases that have followed a benign ulcer. There will be a typical picture of the chronic ulcer, and there is therefore a danger that the minor changes, such as occur with the early onset of carcinoma, may be overlooked. It is in such cases that it is so important for the clinician, who has had his suspicions aroused by a slight change in the symptoms, to warn the radiologist of the possibility of the onset of early carcinoma, so that his attention may be direeted towards the possibility of stight irregularities in the outline of the ulcer crater.

When the disease commences at the pylorus it will, as a rule, whether of the fungating or seirrhous type, give rise to obstruction, and the symptoms then are no longer characteristic of a carcinoma, but are those of mechanical ohstruction; that is to say, there will be the feeling of discomfort and fullness coming on immediately after meals, a certain loss of appetite owing to the secondary gastritis, and the onset of vomiting, which will soon become large in amount and occur at relatively long intervals. Here again the important point to remember is that a carcinomatous pyloric obstruction will only have been present for a relatikely short time, whereas one due to an ulcer may have been in existence or have been slowly developing over many years. In any case, obstruction of the pylorus, of whatever nature, should be subjected to early operation.

Carcinoma situated at the cardiac orifice will in the same way lead to oesophageal obstruction, although if the growth has commenced in the stomach rather than in the oesophagus itself there will probably be a period in which the symptoms are those of a neoplasm of the body of the stemach.

Treatment.

In spite of a great deal of work that has been done along medical lines, there can be no question that at present such methods hold out no hopes of success. The nse of the various colloidal metals-and more especially the theoretically fascinating treatment with colloidal lead-has been relatively widely tried, but cannot yet be said to have male sufficient progress to warrant their general use. Owing to the depth and inaccessibility of the growth, the treatment by massive doses of $x^{\circ}$ rays or radium emanations has not yet sufficiently advanced to hold out a very great hope. Possibly in the near future the use of the radium cannon may revolutionize our ideas in the treatment of sueh growths, but so far this method is in the experimental stage. It may therefore be said that nnquestionably the only treatment to be advocated at present is by operation. Because this is an accepted fact, there is rather a tendency to believe that the outlook with such a method is satisfactory. Unfortunately, careful statistics show that even with an operation the results leave much to be desired. To a very large extent the fault of this lies on our shoulders. Of my 262 cases, 171, or 65.2 per cent., were found at operation to be too far advanced for removal, and although early diagnosis is often a matter of great diffeulty, we must make every effort to lessen so high a percentage. It is true that many patients show so insidious an onset of the disease that they are in an inoperable stage when they first seek medical advice, but that this percentage can be reduced is shown by my own figures. In the first five years there were 81 cases, 60 of which ( 74.1 per eent.) were inoperable. In the second 5-year period there was a very satisfactory improvement: of 91 cases, 50 , or only 56.1 per cent., were inoperable. In the last five years there has been a slight lapse: of 90 cases, 60 , or 66.6 per cent., were inoperable. $\mathbf{F}$ cannot help but think that this lapse is due, in part at least, to the recent exalted claims of the value of the medical treatment of chronic gastric uleers, for so many of this last series had been dirgnosed as chronic ulcer and treated medically until they were inoperable.

It is possible that a more extended trial of the method of treating the exposed growth by massive doses of $x$ rays, as advocated by Digby Chamberlain,' may convert some of the apparently inoperable growths into conditions which can be removed with a good prospect of permanent cure. Even when the growth is removable the end-results are capable of much improvement. The published figures- of such results show a remarkable diversity, some having claimed 40 per cent. of three-year and 26 per cent. of fireyear cures, whereas others have found that only about 1 per cent. of the operated cases have lived for five years. I have already stated that of my 262 cases only $\mathbf{g}$ can be regarded as possible cures, and in a series $I$ have previously recorded, of 117 cases carefully followed for a minimum of four years, of whom 62 were treated by partial gastrectomy, only 4-that is, 6.4 per cent.-were still alire and well fifteen, twelve, ten, and seven years respectively after operation, although several of the others who had died of recurrences had lived in comfort for as long as three and four years. It is very doubtful whether this percentage of recurrences can in any way be prevented by the use of more extensive operations. It is my own custom to perform as wide a partial gastrectomy as possible, so that very often only one or two inches of the fundus of the stomach are left, and in many cases the glands are removed from around the coeliac axis. It is in the combined use of radium with partial gastrectomy that at present $I$ am looking for more hopeful results. If only a small percentage of these recurrences can be prevented much may be done to improve the operatire results.

\section{Indications for Operation.}

Since it is by operating in the earliest possible stage that we can best hope to improve our results and to make it possible to perform a partial gastrectomy in the 66 per cent. of cases which at present are inoperable, we must consider carefully upon what grounds other than a definite diagnosis we are justified in advising operation. It is selfevident that if a patient of midklle age presents himself with a short history of perisistent and progressive dyspepsia having the characters described above, which has not vielded to a week's medical treatment, and more especially if the test meal shows an absence of free hydrochloric acid, he must be regarded as probably, if indeed not certainly, suffering from carcinoma of the stomach, and an operation should be advised at the earliest opportunity. If the $x$-ray findings are positive or suggestive, the dragnosis may be regarded as certain, but it is especially in these early cases that the $x$-ray appearances may be so nearly normal that a wroug conclusion may be drawn. Although, if an operation be advised with a negative $x$-ray photograph, the patient may occasionally be found to have only a gastritis, yet his relief on being definitely assured that no carcinoma is present is so great that it will do much to help his recovery. In suggesting such a course of treatment one is aware of the danger of adrocating a routine exploratory laparotomy, a course which is strongly to be deprecated. It is only after a very careful consideration of the symptoms and of the danger of overlooking a carcinoma that an operation should be advised. If the case has been one with a sudden onset and presents the more serious symptoms of hacmorrhage or severe pain, operation can even more confidently be advocated. The condition is then 
almost certain to be one of carcinoma, or in a very few cases where there has been an error of diannosis the underlying condition is most probably one which can only be treated by operative measures.

When the patient has been suffering from a chronic gastric ulcer which has undergone a change in the symptoms suggestive of the onset of carcinoma the course to be pursued is definite. So long persistent an ulcer giving such definite srmptoms onght never to have reached this stage before an operation was undertaken, and the difficulty before the surgeon will be, not whether to operate, but whether to carry out a more extensire partial gastrectoms because of the suggestive symptoms. In this trpe of case the test meal mas still be nornal, and the radiogram mar be characteristic of an ulcer; but there should be no hesitation whatever, if there is the slightest suggestion of a carcinomatous change, either because the srmptoms have become more persistent or less severe, or the appetite has begun to fail, or the romiting has aftered in character and does not relieve the pain, in performing a partial gastrestomy on the assumption that a carcinomatous change is present. I have unhesitatingly pursued this course, anc have never had reason to regret it. In some 10 cases the removed portion of the stomach has shown to the naked eye a characteristic chronic gastric ulcer, but subsequent microscopic investigation has revealed the presence of a carcinomatous change, and the operation therefore has given the patient the chance of a permanent cure. If there is pyloric obstruction, operation must alwars be performed at the earliest opportunity, for it is evident that if a patient of middle age has developed a mechanical obstruction nothing but surgical treatment can overcome the trouble. Nevertheless, cases are still seen where medical treatment, including lavage and diet, has been carried out for some reeks or months until the condition has become hopelessly inoperable. In this variety, as in the last, a careful consideration must be given to the symptoms, and if there is the slightest suggestion that the obstruction is carcinomatous in origin a partial gastrectomy must be carried out rather than a gastro-enterostoms. The only difficulty which will arise is in those cases where there has been a long past history of a pyloric ulcer, for a short history of pyloric obstruction in an adult is almost rertainly careinomatous. When secondary to an ulcer the main points upon which a differential diagnosis will be made are tho rapidity of the onset of the obstruction, the relatively early fall in the acid in the test meal, the loss of appetite, and the presenee of a tumour.

The mere presence of a tumour in the region of the stomach is no counter-indication to operative treatment, nor, indeed, is its size or apparent mobility. It may be thought that the tumour is so big that it is certain to be inoperable, but massive carcinomata may occur on the greater curvature which give rise to a tumour 3 to 4 inches in diameter and yet are easily removable. The only counterindication to operation in a tumour of this nature is the definite evidence of secondary deposits. Most frequently they show themselves as nodules in the recto-vesical pouch, which can be felt by rectal examination, as enlargements of the liver, or in the presence of ascites. It is true that the larger the tumonr and the more fixed it appears to be the more likely is the case to be inoperable, but it has always been $\mathrm{my}$ experience that in doubtful conditions it is wiser to carry out the operation. Should this not be performed the relatives will always feel, after the death of a patient, that if onls an operation had been carried out he might have been saved, whereas when it has been performed and the condition found to be inoperable ther will consider that at least every attempt had been made to save him.

of the technical steps in perfornaing the partial gastrectomy I need say but little. There should be a wide and free removal of the lesser and greater omenta. The subpyloric glands around the head of the pancreas must be carefully dissected away. The coronary gromp of glands must be removed as high as possible, and it is my own custom in cases of doubt to dissect the glands from around the coeliac axis. The resection of the stomach should in all cases include about seven-eighths of the viscus, and the anastomosis can be best performed br the end-to-side method of Polya. It is my own custon to do this by the old method of bringing a loop of jejunum up throngh the mesocolon, and making the anastomosis some 4 to 5 inches from the flexure. Many surgeons have abandoned this method and make the antecolic anastomosis, but in $\mathrm{my}$ hands the posterior method-if a small loop is left-is so satisfactory that $I$ have seen no reason to change it.

It will naturally be thought that with the modern progress of radium trcatment some use may be made of thi. form of therapy, but with our present uncertainty of the results of this method of treatment it has seemed useless to attompt to use it in the advanced and inoperable cases, for this would mean a wide application to the stomach, to the glands, and probably to the liver, but it does hold out a hope that if used in combination with operation it might do something to prevent or lessen the high recurrence rate. It has been my experience that the cases which recur usually show a large deposit either around the head of the pancreas or in the neighbourhood of the coeliac. axis. I have therefore in my more recent cases been using radium after all partial gastrectomies, and have been inscrting 12 milligrams around the coeliac axis and 8 milligrams around the head of the pancreas. These tubes are left in situ for four days. It is, of course, at present impossible to say what the value of this method will be, and indeed we shall not have any accurate statistics until at least five years have elapsed. Our present experience does show, however, that the insertion of the tubes may. cause a little post-operative vomiting, but so far this has not been sufficient to make us abandon its use, and we still have high hopes that satisfartory results will ensue and that the number of lasting cures will be considerably increased.

ReFerExces.

${ }^{1}$ Chambrrlain, Dighty: A New Method of Approach in Gastric Surgery, Jiritish Medical Journal, Fehruary 23rd, 1929, p. 343 Ucett, W. J. M. : The Relationship of Carcinoma and Callous Gastric
Uleer, Surg., Gynecol. and Obstet., vol. xlvi, No. 2, February, 1928, p. 199

Stcwart, M. J.: The General Relation of Gastrie Careinoma to Ulcer, British Metical Journat, November 14th, 1925, p. 882

Stimson, J. W. Colloid Carcinama of the Stomach, Surg., Gynecel. and (A) stet., vol. xlvi, No. 2, Ectruary, 1928, p. 180

Sulivan, R. OCarcinoma of the Stomach in Young People, Surg., Walton, A. J. : Carcinoma of Stomach, Lancet, September 1st, 1928, p. $4 \geq 8$.

\section{SERLA TREATHENT OF THE PNEUNOCOCCES PNEUMONIAS."}

\author{
JESSE G. M. BULLOWA, M.D.,
} CLINICAL PROFESSOR OF MEDICINE, NEW YORT UNJVERSTTY.

Curvical classification of the pneumonias in accordance with their probable pathological findings seems to be useful only in so far as they suggest the etiology. Snch classifications may prove clinically disastrous, as when a diagnosis of broncho-pneumonia or " influenza preumonia" is made, and the actual condition is Type I pneumococcus pneumonia. Such cases are eommon. Two were recently investigated by us; both proved fatal, and were due to pneumococcus Type I, and therefore probably amenable to serum therapy. Ther were not typed until they came under our observation very late in their course.

Etiological cdassification of the pneumonias is of value if it holps to determine treatment and prognosis. Until it was definitely demonstrated that serum treatment was useful in at least one of the pneumococcus pneumonias a further subdivision of the miscellaneous types of organisms that constitute the miscellaneous group, or Group IV, was, for practical men, scarcely worth the effort involved in separating them.

As the result of the carefully controlled experiment at Harlem, Bellevue, aud New York Hospitals, carried on under the direction of Dr. William H. Park, it has been shown statistically that in Type I pneumonias the mortality can be reduced by the use of the refined antibacterial serum now available, so that instead of one patient in three, one

* Read before the Eastern Medical Society, February 8th, 1929. From the Medical Service, Harlcm Flospital (Lewis K. Neff, Director) and the 